\title{
ABRIGO TEMPORÁRIO PARA MORADORES EM SITUAÇÃO DE RUA DE PRESIDENTE PRUDENTE - SP
}

Jacqueline Magalhães Saab, Mayara Pissutti Albano, Fabrícia Dias da Cunha de Moraes Fernandes Borges

Universidade do Oeste Paulista - UNOESTE, curso de Arquitetura e Urbanismo, Presidente Prudente, SP. E-mail: ma.albano@unoeste.br

\section{RESUMO}

Não há consenso relativo ao surgimento de população em situação de rua no Brasil, apenas alguns apontamentos nesse sentido, contudo, após a Constituição de 1988, as políticas sociais ganharam maior visibilidade e foram criadas leis e decretos que auxiliam até hoje as pessoas que se encontram na referida situação. Em 2010, instituiu-se o Centro de Referência Especializado para População em Situação de Rua - Centro POP e o Centro de Acolhimento no Brasil, cujo objetivo é oferecer auxílio a esses indivíduos. O município de Presidente Prudente inaugurou os Centros apenas em 2012. Após algumas mudanças, os serviços ofertados não são capazes de suprir as necessidades desta população. Devido a tal fato, a pesquisa proposta pretende elaborar análises para escolha de um local adequado para implantação um abrigo temporário destinado aos moradores em situação de rua de Presidente Prudente - SP, bem como desenvolver diretrizes para o respectivo projeto arquitetônico.

Palavras-chave: População em Situação de Rua, Centro POP, Abrigo Temporário, Diretrizes Projetuais, Presidente Prudente - SP.

\section{TEMPORARY SHELTER TO DWELLERS IN STREET SITUATION OF PRESIDENTE PRUDENTE - SP}

\begin{abstract}
There is no consensus regarding the emergence of homeless people in Brazil, only a few notes in this regard, however, after the 1988 Constitution, social policies gained greater visibility and laws and decrees were created that help people who are In that situation. In 2010, the Specialized Reference Center for Population in Situation of the Street - POP Center and the Reception Center in Brazil was established, whose objective is to offer assistance to these individuals. The municipality of Presidente Prudente inaugurated the Centers only in 2012. After some changes, the services offered are not able to meet the needs of this population. Due to this fact, the proposed research intends to elaborate analyzes to choose a suitable place for implantation a temporary shelter destined to the residents in street situation of Presidente Prudente - SP, as well as to develop guidelines for the respective architectural project.
\end{abstract}

Keywords: Population in Situation of Street, POP Center, Temporary Shelter, Design guidelines, Presidente Prudente - SP.

\section{INTRODUÇÃO}

A problemática relativa à população em situação de rua está cada vez mais relevante, principalmente nos grandes centros urbanos. Segundo o Censo do Instituto Brasileiro de Geografia e Estatística (IBGE), de 2010, há cerca de 1,8 milhões de moradores vivendo nas ruas. Em 2016, o número aumentou $10 \%$.

Klaumann (2014) afirma que a partir do final da década de 1980 o Brasil passa por um processo de democratização, a Constituição Federal de 1988 traz consigo uma força que 
impulsiona as políticas de assistência social, assim como a população em situação de rua ganha olhares diretos. De acordo com o Art. 5o da Constituição Federal (1988), "Todos são iguais perante a lei, sem distinção de qualquer natureza, garantindo-se aos brasileiros e aos estrangeiros residentes no País a inviolabilidade do direito à vida, à liberdade, à igualdade, à segurança e à propriedade".

De acordo com (BRASIL, 2011), foi sancionada a Política Nacional de Assistência Social (PNAS) em 2004, que oferece proteção à população em situação de rua. Em 2005 o Movimento Nacional da População de Rua - MNPR intensificou-se; e ocorreu o I encontro Nacional de População em Situação de Rua culminando no começo da formulação da Política Nacional para População em Situação de Rua, visando a denunciar as situações de violência física e moral vividas pelos moradores no dia a dia e as operações de limpeza realizadas em diversas cidades (KLAUMANN, 2014).

Em 2009, após quatro anos de estruturação foi sancionada em 23 de dezembro, através do Decreto no 7.053, a Política Nacional para a População em Situação de Rua. "Esta Política surgiu como forma de orientar a construção e execução de políticas públicas voltadas especificamente para este segmento da sociedade [...]" (PEREIRA; SANTOS, 2013, p. 4).

A organização da Política Nacional para População em Situação de Rua define as principais áreas de atendimento para essa população, dentre elas estão políticas de Assistência Social, Saúde, Habitação e Trabalho e Renda, além da Segurança Alimentar e Nutricional e Educação (PEREIRA; SANTOS, 2013). Em 2010 o Ministério do Desenvolvimento Social e Combate à Fome (MDS) adotou procedimentos para que a referida Política fosse consolidada através do Cadastro Único para Programas Sociais do Governo Federal (Cadúnico), onde foram criados formulários para cadastrar os moradores em situação de rua. Essa iniciativa, "[...] deve auxiliar na formulação de políticas específicas para essa população e promover o acesso aos programas sociais nas três esferas de governo" (PEREIRA; SANTOS, 2013, p. 5).

Apesar da significativa evolução, dos grandes feitos representados pela formulação de políticas públicas, conquistados pelos moradores através dos anos, ainda existem muitos problemas sociais e falta de estrutura adequada para o auxílio a essa população. É necessária a devida atenção das diferentes esferas governamentais para que essa realidade mude.

O município de Presidente Prudente - SP, objeto de estudo da presente pesquisa, possui uma população de 223.749 habitantes segundo estimativas do IBGE de 2016. Considerada uma cidade de porte médio, Presidente Prudente enfrenta problemas sociais, um deles é o difícil atendimento à população em situação de rua. De acordo com um levantamento feito pela Secretária de Assistência Social (SAS), a referida cidade possui cerca de 140 pessoas em situação de rua; $50 \%$ já recebeu ajuda e se encontra em tratamento dentro de algum programa social local.

Presidente Prudente possui duas instituições financiadas pela prefeitura municipal: o Centro POP e o Centro de Acolhimento, destinadas a apoiar os moradores em situação de rua. Ambas não possuem a estrutura suficiente para o atendimento da população necessitada de auxílio. De acordo com informações do Centro POP, as instituições enfrentam problemas como a falta de recursos para alimentação e acolhimento, justificando assim, a relevância social da presente pesquisa.

Em resposta ao problema propôs-se como objetivo da pesquisa desenvolver análises que embasem a escolha de um terreno adequado para implantação de um abrigo temporário para pessoas em situação de rua, bem como diretrizes para o respectivo projeto arquitetônico de um abrigo onde haja diferentes tipos de acolhimento, com espaços destinados aos diferentes perfis: homens, mulheres, gravidas, famílias, idosos e aos animais de estimação, em horários diversos. Além de áreas para atendimento às necessidades básicas como alimentação, higiene, saúde, descanso e lazer. Por fim, espaços livres que tragam uma relação de liberdade e atestem ao morador em situação de rua, o direito de ir e vir. 


\section{METODOLOGIA}

A metodologia utilizada nesta pesquisa se deu através de investigação qualitativa, utilizando-se de levantamento bibliográfico, de pesquisa documental, de levantamentos físicos territoriais e arquitetônicos in locu após a escolha do terreno para desenvolvimento das respectivas análises.

Num primeiro momento foi realizado levantamento bibliográfico em livros e periódicos com as principais obras referentes ao assunto trabalhado. Numa segunda fase, foram desenvolvidas pesquisas documentais para verificação de políticas públicas, legislação que regulamente os espaços destinados ao atendimento de pessoas em situação de rua, bem como pesquisas que auxiliem na descoberta do perfil desta população. Na terceira fase foram desenvolvidas visitas às instituições existentes em Presidente Prudente que prestam serviços de atendimento às pessoas em situação de rua, para que fosse possível realizar o levantamento espacial através de fotografias que esclareceram o funcionamento do local e assim, seja subsídio para elaboração das diretrizes projetuais.

Após o entendimento do embasamento levantado, foi escolhido um terreno adequado à implantação de um centro de acolhimento provisório e posteriormente foram realizados levantamentos in locu, para a realização de peças gráficas (plantas, cortes, mapas) com as análises morfológicas do lote e seu entorno que foram fundamentais para elaboração das diretrizes projetuais, que correspondem à última fase da pesquisa.

\section{PERFIL DOS MORADORES EM SITUAÇÃO DE RUA DO BRASIL E DE PRESIDENTE PRUDENTE}

As características e análises sobre a população em situação de rua, estão baseadas em pesquisas realizadas no âmbito nacional pelo Ministério do Desenvolvimento Social e Combate à Fome - MDS e também no âmbito municipal, realizada por uma estudante de Serviço Social em 2014. Entre agosto de 2007 a março de 2008 foi realizada uma Pesquisa Nacional Sobre a População em Situação de Rua, fruto de um acordo de cooperação entre a UNESCO e o MDS, que detectou 31.922 moradores em situação de rua acima de 18 anos, vivendo em praças, calçadas, ruas, viadutos, tuneis, depósitos, prédios abandonados ou que pernoitem em abrigos, albergues, casas de apoio, acolhidas e igrejas.

Após a análise da pesquisa, revela-se alguns pontos relevantes. A maioria dos moradores não está nas ruas por decisão própria, eles foram levados a isso por problemas pessoais. $\mathrm{O}$ uso de drogas é um dos principais fatores que levam essa população a viver nas ruas, em muitos casos ele se torna uma forma de se aquecer em noites frias. O relacionamento com a família muitas vezes define a decisão do indivíduo de ir ou não para as ruas. Percebe-se que apesar dos problemas citados, os moradores almejam um emprego para se sustentar ou sustentar seus estudos, e não recebem a ajuda necessária.

De acordo com uma pesquisa de Serviço Social de Presidente Prudente, realizada por Silva e Parrão (2012), foi possível caracterizar os moradores em situação de rua da cidade. Segundo a pesquisa, foram entrevistados 36 moradores atendidos no Centro de Referência Especializado em População em Situação de Rua (Centro POP).

Após analises e realizando uma contextualização com a pesquisa executada em âmbito nacional, pode-se concluir que o contexto dos moradores em situação de rua de Presidente Prudente se assemelha em muitos pontos com a pesquisa realizada pelo MDS em 2008. Primeiramente na questão relacionada ao gênero, a maioria dos moradores são homens, cerca de 64\%. Um dos motivos que levam essa população a essa situação é o problema com drogas, muitos consomem após ocuparem as ruas porem a maioria consome antes de chegar a essa situação, segundo a pesquisa, 97\% admitem usar drogas, um dado relevante. Os dados reforçam a importância do tema e futuro projeto (SILVA; PARRÃO, 2012). 
A Lei Municipal n.5005/97 decretada pela Câmara Municipal de Presidente Prudente - SP foi criada para organizar as Secretarias e suas competências dentro do município. Mediante a lei, foi determinada a criação do Departamento de Proteção Social Especial que realiza a coordenação de todos os serviços oferecidos pela proteção especial no município de Presidente Prudente.

Mesmo com o embasamento legal, hoje o município supracitado não consegue atender adequadamente a população em situação de rua por fata de infraestrutura. Os edifícios que abrigam tais serviços são improvisados ou não oferecem as condições necessárias para tal, sendo assim, o presente trabalho desenvolveu análises que embasaram escolha de um terreno onde possa ser construído um abrigo temporário e também desenvolveu as diretrizes para dar suporte à execução do projeto arquitetônico do mesmo.

\section{ESCOLHA DO TERRENO}

O local escolhido para a implantação do projeto possui uma boa localização, pois segundo as orientações técnicas do Centro Pop, desenvolvidas pelo MDS (2011), a implantação do projeto deve ter uma boa centralização e fluxo de pessoas, além de estar próxima dos locais que os moradores em situação de rua costumam permanecer.

O terreno possui uma área urbana de $2177,12 \mathrm{~m}^{2}$, localizado na Avenida Brasil, Vila São Jorge em Presidente Prudente - SP, fica próximo à rodoviária, em uma área da cidade onde há muita concentração de moradores em situação de rua, cumprindo assim, as orientações pertinentes à escolha do local.

\section{FIGURA 1 - Localização do terreno escolhido}
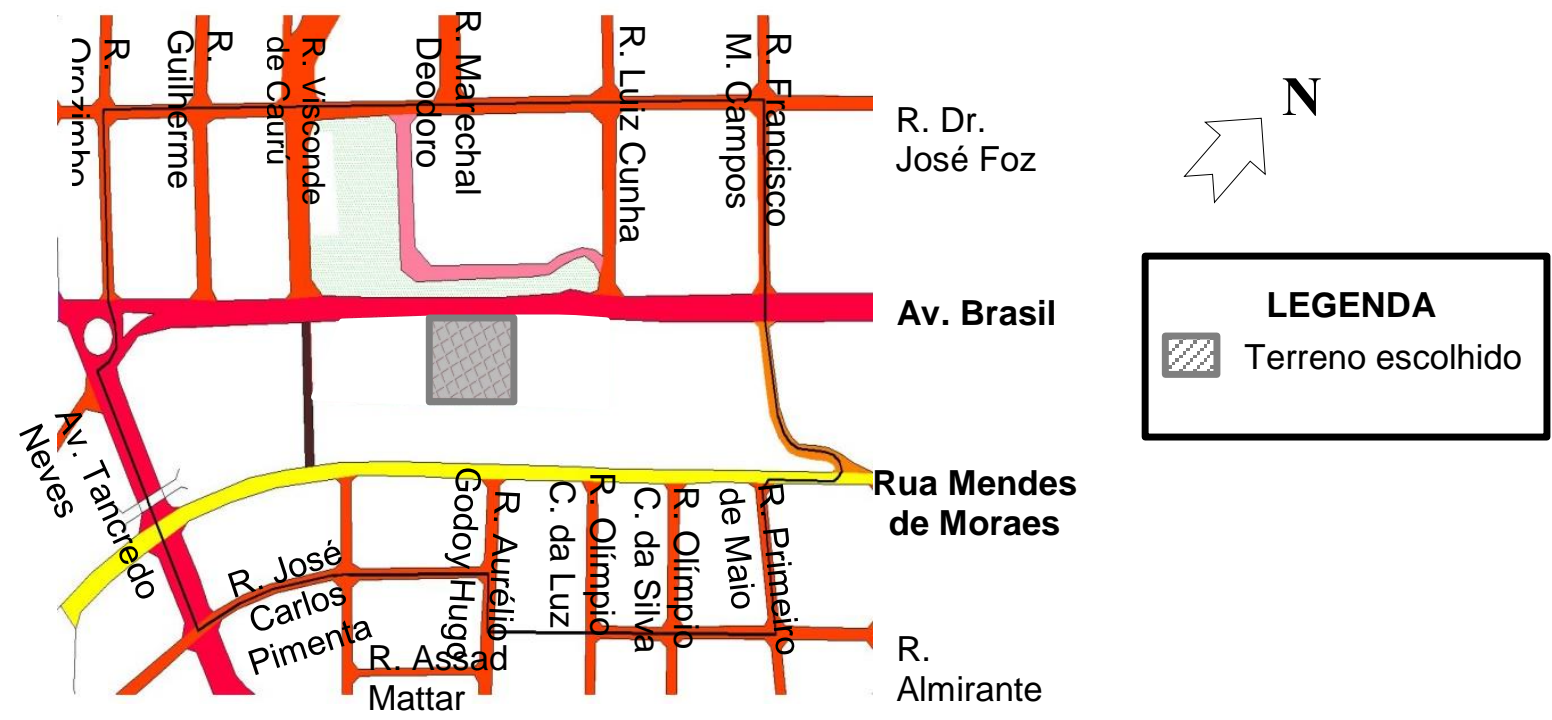

Fonte: Prefeitura Municipal, organização: autores, 2017.

\section{DIRETRIZES PROJETUAIS E PROGRAMA DE NECESSIDADES}

A proposta projetual corresponde a concepção de um abrigo temporário destinado aos moradores em situação de rua de Presidente Prudente - SP. Para tal, deverá seguir as orientações do Ministério do Desenvolvimento Social (2011). O edifício deverá conter um setor destinado à administração e atendimento à saúde, como apresentado na Tabela 1.

TABELA 1 - Apresentação dos ambientes do Setor Administrativo

\begin{tabular}{|l|c|}
\hline \multicolumn{1}{|c|}{ SETOR - ADMINISTRAÇÃO } \\
\hline \multicolumn{1}{|c|}{ AMBIENTE } & QUANTIDADE \\
\hline Recepção e acolhida inicial & 1 \\
\hline Sala da coordenação & 1 \\
\hline
\end{tabular}




\begin{tabular}{|c|c|}
\hline Sala de administração & 1 \\
\hline Sala de reunião & 1 \\
\hline $\begin{array}{l}\text { Sala de atendimento individualizado, familiar ou em } \\
\text { pequenos grupos }\end{array}$ & 2 \\
\hline Almoxarifado & 1 \\
\hline Copa & 1 \\
\hline Banheiro feminino & 1 \\
\hline Banheiro masculino & 1 \\
\hline Guarda de pertences & 1 \\
\hline \multicolumn{2}{|l|}{ SETOR - SAÚDE } \\
\hline Sala de espera & 1 \\
\hline Banheiro feminino & 1 \\
\hline Banheiro masculino & 1 \\
\hline Banheiro feminino para funcionários com vestiário & 1 \\
\hline Banheiro masculino para funcionários com vestiário & 1 \\
\hline Sala psicologia e psiquiatria & 2 \\
\hline DML & 1 \\
\hline
\end{tabular}

Fonte: MDS (2011), organizado pelos autores, 2017.

Também deverá constar um setor destinado à alimentação e apoio e ambientes destinados à higiene e descanso (Tabela 2). Além de ambientes destinados a ressocialização dos moradores, ou seja, o local destinado ao ensino, como por exemplo, oficinas, salas de jogos, e a horta comunitária (Tabela 3).

TABELA 2 - Ambientes do setor de alimentação, do setor de descanso e apoio

\begin{tabular}{|c|c|}
\hline \multicolumn{2}{|c|}{ SETOR - ALIMENTAÇÃO E APOIO } \\
\hline AMBIENTE & QUANTIDADE \\
\hline Refeitório & 1 \\
\hline Cozinha & 1 \\
\hline Dispensa & 1 \\
\hline Lavabo masculino e feminino & 2 \\
\hline \multicolumn{2}{|c|}{ SETOR - DESCANSO E APOIO } \\
\hline Dormitório feminino & 5 \\
\hline Dormitório masculino & 5 \\
\hline Banheiro masculino & 1 \\
\hline Banheiro feminino & 1 \\
\hline
\end{tabular}

Fonte: MDS (2011), organizado pelos autores, 2017.

TABELA 3 - Ambientes do setor de ressocialização

\begin{tabular}{|l|c|}
\hline \multicolumn{1}{|c|}{$\begin{array}{c}\text { SETOR - RESSOCIALIZAÇÃO E APOIO } \\
\text { AMBIENTE }\end{array}$} & QUANTIDADE \\
\hline Biblioteca & 1 \\
\hline Oficina de costura & 2 \\
\hline Oficina de pintura & 2 \\
\hline Oficina de marcenaria & 2 \\
\hline Banheiro feminino & 1 \\
\hline Banheiro masculino & 1 \\
\hline
\end{tabular}


Canil

Horta comunitária
1

1

Fonte: MDS (2011), organizado pelos autores, 2017.

\section{CONCLUSÃO}

Após analises realizadas, conclui-se de que mesmo com inúmeras políticas públicas destinadas a esse seguimento, o perfil dos moradores em situação de rua, tanto no âmbito nacional como municipal se assemelha, devido à necessidade ser basicamente a mesma, a falta de serviços e estrutura necessária para atendê-los. A criação de um abrigo destinado a essa população que forneça os subsídios necessários para uma qualidade de vida digna, torna-se então, essencial.

\section{REFERÊNCIAS BIBLIOGRÁFICAS}

BRASIL, Ministério do Desenvolvimento Social e Combate à Fome - MDS. Orientações Técnicas: Centro de Referência Especializado para População em Situação de Rua - Centro Pop. v. 3. Brasília, 2011. Disponível em: <http://cimos.blog.br/atuacao/pessoas-em-situacao-derua/documentos/> Acesso em: 25 mar. 2017.

BRASIL, Ministério do Desenvolvimento Social e Combate à Fome - MDS. Pesquisa Nacional Sobre a População em Situação de Rua: Sumário Executivo, 2008. Disponível em: <http://www.rcdh.es.gov.br/pagina/popula\%C3\%A7\%C3\%A3o-em-situa\%C3\%A7\%C3\%A3o-de-rua >. Acesso em: 25 mar. 2017.

INSTITUTO BRASILEIRO DE GEOGRAFIA E ESTATístICA. IBGE, 2010. População Estimada, 2016. Diretoria de Pesquisas, Coordenação de População e Indicadores Sociais. Presidente Prudente: IBGE, 2016. Disponível em: <http://cod.ibge.gov.br/2VY> Acesso em: 11 abr. 2017.

KALUMANN, A. R. Moradores de rua - Um enfoque histórico e socioassistencial da população em situação de rua no Brasil: A realidade do Centro POP de Rio do Sul/ SC. (Monografia de Especialização em Educação) - UNIDAVI, Ituporanga - SC, 2014.

LEMOS, C. O que é Arquitetura. 7. ed. São Paulo: Brasiliense, 2003.

MACIEL. C. A. Arquitetura, projeto e conceito. Disponível em: <http://www.vitruvius.com.br/revistas/read/arquitextos/04.043/633> Acesso em: 15 mai. 2017. PEREIRA, T; SANTOS, P. RUAS e População em situação de Rua: Texto 2. Pernambuco, 2014. Disponível em: <http://portalsocial.sedsdh.pe.gov.br/sigas/suasrh/?p=2013> Acesso em: 27 mar. 2017.

SILVA, A. D.; PARRÃO, J, A. Diagnóstico Acerca da População em Situação de Rua: Um Estudo no Creas Pop do Município de Presidente Prudente. In: ENCONTRO DE INICIAÇÃO CIENTíFICA - ETIC, v. 9, n. 9, 2012. 